\title{
Viruses Associated with Rusty Mottle and Twisted Leaf Diseases of Sweet Cherry Are Distinct Species
}

\author{
D. E. V. Villamor and K. C. Eastwell
}

Department of Plant Pathology, Washington State University, Irrigated Agriculture Research and Extension Center, Prosser 99350. Accepted for publication 2 July 2013.

\begin{abstract}
Villamor, D. E. V., and Eastwell, K. C. 2013. Viruses associated with rusty mottle and twisted leaf diseases of sweet cherry are distinct species. Phytopathology 103:1287-1295.

Virus RNA sequences related to those of the family Betaflexiviridae were amplified from trees affected with the following diseases: cherry twisted leaf, apricot ring pox, cherry necrotic rusty mottle, cherry rusty mottle, and cherry green ring mottle. Phylogenetic analysis of virus sequences obtained from these diseased trees from western North America, along with published sequences of Cherry green ring mottle virus (CGRMV) and Cherry necrotic rusty mottle virus (CNRMV), re-

vealed four major clades. Segregation into these four populations correlated with distinct symptom expression on woody indicators, suggesting that each clade represents a distinct virus species within the family Betaflexiviridae. The viruses occupying each clade were designated clade I: Cherry twisted leaf associated virus, clade II: CNRMV, clade III: Cherry rusty mottle associated virus, and clade IV: CGRMV. Potential recombination events were predicted to occur within and between these viruses, the latter being strongly supported by incongruent phylogenies. Examination of frequency distribution data derived from pairwise sequence comparisons of coat protein coding sequences resulted in a proposal for alternative guidelines for species demarcation for this family of viruses.
\end{abstract}

The rusty mottle disease group and cherry twisted leaf disease (CTLD) of sweet cherry (Prunus avium) constitute a group of graft-transmissible diseases whose etiology has long been assumed to be viral in nature (28-30). The former is a complex assemblage of diseases that includes cherry rusty mottle disease (CRMD) and cherry necrotic rusty mottle disease (CNRMD). CRMD is further subdivided into mild and severe forms; the latter is characterized by more extensive loss of symptomatic leaves in late summer and a faster rate of tree decline relative to mild forms (37). A disease similar to CRMD was reported in England (26) but was later established to be different from the North American type, resulting in further subdivision of CRMD into American and European types (24). Yellow mottling associated with the European type of CRMD is concentrated along the veins (31) while symptoms of the American type occur predominantly between veins and are accompanied by yellow to red chlorotic rings in some affected trees (37). Symptoms of CNRMD closely resemble CRMD but, on some cherry varieties, also include the induction of angular necrotic leaf spots that break away later in the season. Other diseases presumed to be caused by an agent related to that of CNRMD include Lambert mottle, Frogmore canker, and cherry bark blister (17,27,34). CTLD is characterized by abrupt kinking of the leaf midrib that results in leaf twisting in many sweet cherry cultivars, particularly 'Bing', 'Rainier', and 'Lambert'. The agent causing apricot ring pox (ARPD) is presumed to be an isolate of the agent associated with $\operatorname{CTLD}(8,18)$.

Historically, these diseases had a severe impact on sweet cherry production in the United States. Reports indicate that, in 1942, $2.9 \%$ of the sweet cherry trees surveyed in Yakima, Douglas, and Chelan Counties of Washington State were infected with CRMD,

\section{Corresponding author: K. C. Eastwell; E-mail address: keastwell@wsu.edu}

* The $\boldsymbol{e}$-Xtra logo stands for "electronic extra" and indicates that the online version contains two supplemental figures.

http://dx.doi.org/10.1094/PHYTO-05-13-0140-R

(c) 2013 The American Phytopathological Society with as many as $34.0 \%$ of the trees in a single orchard being symptomatic (4). In the same year, CTLD was reported for the first time in Washington State, where $73.8 \%$ of the trees in one orchard in Yakima County were affected by the disease (4). Although the occurrences of these diseases were dramatically reduced by the establishment of fruit tree virus certification programs in the 1950s, sporadic occurrences of these diseases persist.

A key element in developing an effective disease management strategy is understanding etiology of the disease, usually through fulfilling Koch's postulates. Because it is difficult to isolate and mechanically transmit viruses associated with many fruit tree diseases, and infectious clones of many viruses are elusive, establishing a consistent association of virus sequences with disease has been the most practical path forward. Identification of virus sequences is also critical for the development of virus-specific molecular-based detection assays such as reverse-transcription polymerase chain reaction (RT-PCR) that can be employed to further advance the robust correlation between the presence of virus sequences and the occurrence of disease symptomatology.

Cherry green ring mottle virus (CGRMV) occurs widely in sweet cherry but does not induce acute symptoms in this host. Unlike CTLD, ARPD, and the rusty mottle group of diseases, the etiology of cherry green ring mottle disease (CGRMD) has been established by partial purification of a filamentous virus and subsequent disease induction by the virus in sour cherry $(P$. cerasus) (39). The full genome of CGRMV was determined $(6,38$, 40) and showed significant similarity to North American Cherry rusty mottle associated virus (CRMaV), as well as to Cherry twisted leaf associated virus (CTLaV) and Cherry necrotic rusty mottle virus (CNRMV) $(11,16,32,36)$, suggesting that the viral agents of these diseases are closely related.

Identification of viruses associated with several diseases of sweet cherry has progressed. Recently, genomic virus sequences were determined from sources of CRMD and the virus was named CRMaV (36). A full genomic sequence of CNRMV was reported (32) but direct evidence that this virus induces the corresponding disease is currently limited. A high molecular weight 
double-stranded RNA $(10,41)$ and a flexuous closterovirus-like particle (12) were associated with CTLD. Reference has also been made to a virus genomic sequence associated with CTLD designated as CTLaV (11) but, at the time of this writing, this sequence has yet to be deposited in a public database. Aside from the assumption that the causal agent of ARPD is closely related to the CTLD agent, no virus sequence has been formally associated with ARPD.

This study was initiated to identify viruses associated with CTLD, ARPD, and CRMD, and to correlate the specific virus sequences with disease symptoms. The development and use of virus-specific primers for the RT-PCR detection of individual viruses associated with each disease was used to corroborate these relationships. Results revealed frequent occurrence of these viruses as mixed infections and provide evidence for potential recombination events between these viruses.

\section{MATERIALS AND METHODS}

Disease sources. Twenty-two trees exhibiting symptoms were selected for the characterization of virus-like sequences associated with diseases under investigation. Of these, 15 were maintained in the screenhouse collection of the Clean Plant Center Northwest (CPCNW) at Washington State University, Prosser. The remaining seven symptomatic trees were collected from orchards in different cherry production areas of Washington State. Two additional source trees of ARPD were included in the phylogenetic analysis but were not subjected to virus indexing on woody hosts: ARPD source tree C3 from the Canadian Plant Virus Collection, Agriculture and Agri-Food Canada, Summerland, BC, Canada and ARPD source tree 95CI206 from CPCNW.

Biological woody indexing. Two bark patches from each of 22 virus sources were grafted onto woody indicators (four replicate indicator trees per virus source): P. avium 'Bing' and 'Sam' and $P$. serrulata 'Kwanzan'. Symptom expression was monitored 45 to 90 days after inoculation. The following source trees served as reference sources for each disease: 95CI192R3 for CRMD, 103-13 for CNRMD, 103-15 for CTLD, 95CI205R1 for ARPD, and 02F23rD for CGRMD. Ungrafted indicators served as healthy controls.

RNA extraction, cloning, and sequencing. Total RNA extraction from dormant buds followed by RT-PCR using the Fovea2/AdPr primer pair, cloning, and sequencing were described previously (36). Ten cloned amplicons from each source tree were sequenced. The presence in these 22 trees of other infectious agents that include other cherry viruses, viroids, bacteria, and phytoplasma was also determined by RT-PCR assays, as previously described (36).

Primers specific to virus sequences associated with CRMD, CTLD, CNRMD, and CGRMD (Table 1) were designed from conserved regions of putative coat protein $(\mathrm{CP})$ gene sequences of amplicons obtained with primers Fovea2/AdPr. The ability of each primer pair to detect its corresponding sequence was tested in a one-tube RT-PCR format using the SuperScript III One-Step RT-PCR System with Platinum Taq (Life Technologies Corporation, Carlsbad, CA) following the manufacturer's recommendation, with the addition of $14 \mu \mathrm{g}$ of nonacetylated bovine serum albumin (20) and $0.5 \mu \mathrm{l}$ of Superscript III/Platinum Taq mix per $25-\mu l$ reaction. Total RNA extracted from individual virus source trees or from pooled leaves of graft-inoculated woody indicators was tested with each primer pair.

Sequence analysis. Nucleotide sequences derived by RT-PCR amplification products obtained with primers Fovea2/AdPr were assembled using the BioEdit program (7). After flanking sequences were removed, the nucleotide sequences of the putative $\mathrm{CP}$ coding region and the $3^{\prime}$-untranslated region ( $3^{\prime}$-UTR) were multiply aligned using the ClustalW (9) implementation of the MEGA program package, version 5 (35). Phylogenetic trees were constructed using the neighbor-joining algorithm with 1,000 bootstrap replicates; branches supported by bootstrap values $<60 \%$ were collapsed. The CP nucleotide sequences of CNRMV and CGRMV from other geographic regions were obtained from GenBank and used in alignment and tree construction.

Recombination analysis. The close relationship among CNRMV, CRMaV, CTLaV, and CGRMV sequences and their presence as mixed infections in trees created an environment conducive for recombination. The possible existence of recombination events in the CP and 3'-UTR region was evaluated using recombination detection programs of RDP3 (19). Included in this analysis were sequences from GenBank representing three and four isolates of CNRMV (CNRMV-Ger, GI:8650446; CNRMV-FC4, GI:167600654; and CNRMV-FC5, GI:167600662) and CGRMV (CGRMV-N, GI:22506836; CGRMV-P1C124, GI:11830817; CGRMV-F9, GI:408355234; and CGRMV-S10, GI:408355242), containing full-length CP and 3'-UTR sequences. Recombination events detected by at least four programs were selected and considered to be authentic recombination events (25).

\section{RESULTS}

Pathogen profile of source trees. All 22 disease source trees reacted with primer pair Fovea2/AdPr and these source trees were included in the biological indexing experiment. In addition, RTPCR analysis with virus-specific primers revealed many common viruses known to infect sweet cherry (Table 2). The most commonly detected viruses were Prune dwarf virus (PDV), genus Ilarvirus; Prunus necrotic ringspot virus (PNRSV), genus Ilarvirus; and Cherry virus A (CVA), genus Capillovirus in 19, 14, and 12 trees, respectively.

TABLE 1. Specific primers designed for use in the reverse-transcription polymerase chain reaction (RT-PCR) detection of individual viral sequences in sweet cherry (Prunus avium)

\begin{tabular}{|c|c|c|c|c|}
\hline Primer name & Target virus ${ }^{\mathrm{a}}$ & Primer sequences & $\begin{array}{l}\text { RT-PCR annealing } \\
\text { temperature }\left({ }^{\circ} \mathrm{C}\right)\end{array}$ & $\begin{array}{l}\text { Amplicon } \\
\text { size (bp) }\end{array}$ \\
\hline \multicolumn{5}{|l|}{ Forward } \\
\hline CTL-Ia 218CPF & CTLaV-Ia & TCAGCAAGATTAAGGAGGTTG & 60 & 562 \\
\hline CNRM $122 \mathrm{CPF}$ & CNRMV & CTTCAAGAARGAGYGATATTG & 55 & 658 \\
\hline CRM 91CPF & CRMaV & GGGCCCGAYCCTGTCATTCC & 60 & 695 \\
\hline CGRM 98CPF & CGRMV & CTAAGTCCTCCAACCCTCA & 60 & 685 \\
\hline \multicolumn{5}{|l|}{ Reverse } \\
\hline
\end{tabular}


Symptom induction on biological woody indicators. Assessment of symptoms on the woody indicators was performed 45 and 90 days after graft inoculation (Fig. 1; Table 3). Noninoculated indicators did not show any disease symptoms. Using published references as a guide $(24,37)$, symptoms expressed in the source and indicator trees were used to categorize each as CTLD, ARPD, CNRMD, CRMD, or CGRMD.

Phylogeny of putative $\mathbf{C P}$ coding sequences. The primer pair Fovea2/AdPr amplifies $\approx 1.1 \mathrm{~kb}$ spanning from the $3^{\prime}$-UTR to 77 or 80 nucleotides (nt) upstream of the $\mathrm{CP}$ coding sequences of CNRMV and CGRMV. If RT-PCR amplicons from a single source were $>98 \%$ identical at the nucleotide level within the CP coding region, they were treated as a single sequence. It was previously revealed by sequencing three clones of Fovea2/AdPr amplicons that CRMD 95CI192R3 and B48-C, and CNRMD 103-13 each harbored a single virus sequence (36). However, sequencing 10 cloned Fovea2/AdPr products revealed that CRMD 95CI192R3 and B48-C and CNRMD 103-13 each contained two different sequences. One sequence each from CRMD 95CI192R3 and B48-C and CNRMD 103-13 was identical to the previously published sequences from these trees while the additional sequences from each of these trees were assigned separate accession numbers (Fig. 2).

Phylogenetic relationships using $101 \mathrm{CP}$ nucleotide coding sequences (52 from this study and 49 from the public database) revealed four major clades (Fig. 2), designated clades I to IV. Bootstrap values of $>60 \%$ at each node signify the robustness of the resulting phylogenetic tree. Using the corresponding $\mathrm{CP}$ amino acid sequences yielded phylogeny with similar topology (data not shown).

Multiple virus sequences were commonly recovered from a single source tree by amplification with the Fovea2/AdPr primers. For example, 13 source trees were infected with CGRMV, and
CNRMD source 95CI189R2 harbored virus sequences associated with all four clades (Table 3 ).

Correlation between disease symptoms and the virus $\mathrm{CP}$ sequence profile. The phylogenetic grouping of $\mathrm{CP}$ sequences is consistent with the designation of sources based on symptoms; that is, virus sequences obtained from trees designated as CTLD, ARPD, CNRMD, CRMD, and CGRMD sources occupy distinct clades within the phylogeny. Clades I and III are populated with unique sequences from CTLD and CRMD sources, respectively; therefore, viruses within these clades are designated CRMaV and CTLaV. The CTLaV clade consists of sequences derived predominantly from both CTLD and ARPD sources. Clades II and IV are populated by CNRMV- and CGRMV-specific sequences, respectively.

The sizes of the putative $\mathrm{CP}$ coding sequences of the viruses in these four clades vary. Excluding the stop codon, the putative $\mathrm{CP}$ of CRMaV consists of 807 nt (269 amino acids [aa]), CGRMV consists of 804 nt (268 aa), and CTLaV and CNRMV coding regions consist of $801 \mathrm{nt}(267 \mathrm{aa})$.

In addition to yielding sequences of multiple viruses within a single source tree, 8 of the 22 source trees also yielded sequence variants of individual virus species populations with $<98 \%$ sequence identity. The range of $\mathrm{CP}$ nucleotide and amino acid sequence identities between different viruses is presented in Table 4. Overall, the values of sequence identities of the $\mathrm{CP}$ mirror the results obtained from the phylogenetic analysis. A distinct population of virus sequences could not be associated with either ARPD or CTLD within the CTLaV clade; the close relationship between these viruses is supported by the grouping of both disease-associated virus sequences into a single clade.

The association between specific virus sequences and the disease symptoms expressed over the range of indicators was further evaluated by utilizing primers designed specifically to detect

TABLE 2. Symptomatic source trees used in the study

\begin{tabular}{|c|c|c|c|}
\hline Source tree ${ }^{a}$ & Original collection site ${ }^{b}$ & Maintenance host & Viruses detected with virus-specific primers ${ }^{\mathrm{c}, \mathrm{d}}$ \\
\hline \multicolumn{4}{|c|}{ Clean Plant Center Northwest } \\
\hline B48-C & Benton County, WA & Prunus avium 'Bing' & PDV \\
\hline $101-13$ & N/A & P. avium 'Bing' & CMLV, CVA, PDV \\
\hline $103-13$ & N/A & P. avium 'Sam' & PDV \\
\hline $103-15$ & N/A & P. avium 'Bing' & ACLSV, CMLV \\
\hline $02 \mathrm{~F} 23 \mathrm{rD}$ & N/A & P. avium 'Bing' & PDV \\
\hline 04E17R1 & The Dalles, OR & P. avium 'Bing' & ACLSV, PDV, PNRSV \\
\hline 04E36 & Stockton, CA & P. avium 'Bing' & CVA, PDV, PNRSV \\
\hline 95CI189R2 & Wenatchee, WA & P. avium 'Sam' & CVA, PDV, PNRSV \\
\hline 95CI190 & Wenatchee, WA & P. avium 'Sam' & ACLSV, CVA, PDV \\
\hline 95CI191R3 & Wenatchee, WA & P. avium 'Sam' & ACLSV, CVA, PDV, PNRSV \\
\hline 95CI192R3 & Wenatchee, WA & P. avium 'Bing' & CVA, PDV, PNRSV \\
\hline 95CI205R1 & Wenatchee, WA & P. armeniaca 'Tilton' & None detected \\
\hline 98CI73R1 & Moxee, WA & P. mahaleb & PDV \\
\hline 98CI194 & Mattawa, WA & P. avium 'Bing' & CVA \\
\hline 99CI01 & Granger, WA & P. avium 'Bing' & CVA, PDV, PNRSV \\
\hline 95CI206 & Wenatchee, WA & P. armeniaca 'Tilton' & CVA \\
\hline \multicolumn{4}{|c|}{ Commercial orchards } \\
\hline $8079-1$ & Malaga, WA & P. avium 'Bing' & ACLSV, CLRV, CVA, PDV, PNRSV \\
\hline $8099-5$ & Prosser, WA & P. avium 'Bing' & CVA, PDV \\
\hline $8241-2$ & Wenatchee, WA & P. avium 'Bing' & CMLV, CVA PDV \\
\hline $8241-4$ & Wenatchee, WA & P. avium 'Bing' & ACLSV, CVA, PDV, PNRSV \\
\hline $8242-3$ & Wenatchee, WA & P. avium 'Bing' & CVA, LChV-2, PDV, PNRSV \\
\hline $8244-4$ & Malaga, WA & P. avium 'Bing' & CVA, PDV \\
\hline 8265 & Granger, WA & P. avium 'Bing' & CMLV, PDV, PNRSV \\
\hline \multicolumn{4}{|c|}{ Canadian Plant Virus Collection } \\
\hline $\mathrm{C} 3$ & British Columbia, Canada & P. armeniaca 'Hungarian' & CVA \\
\hline
\end{tabular}

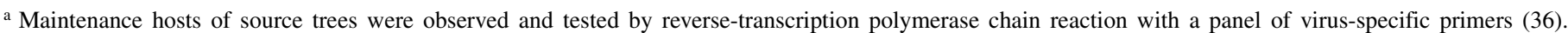
Source trees were from the Clean Plant Center Northwest, Washington State University; commercial orchards; and the Canadian Plant Virus Collection, Agriculture and Agri-Food Canada, Summerland, BC, Canada.

b N/A indicates that information on the place of origin of samples is not available.

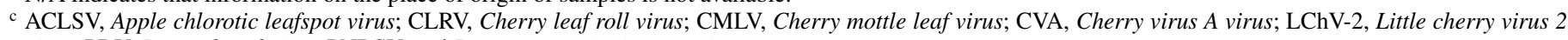
virus; PDV, Prune dwarf virus; PNRSV, and Prunus necrotic ringspot virus.

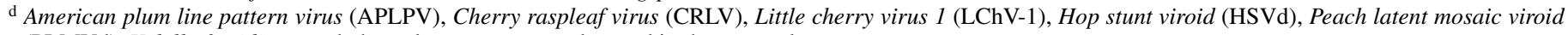
(PLMVd), Xylella fastidiosa, and phytoplasmas were not detected in these samples. 
viruses from each clade of the phylogenetic tree. A common reverse primer, NGRRM-TL CPR, was designed from a conserved region of the $\mathrm{CP}$ coding sequences of the four virus clades, and is located near the $3^{\prime}$-terminal region of the $\mathrm{CP}$ coding sequence. It was used for all viruses under consideration with a forward primer unique to sequences of each virus clade (Table 1), with the exception of clade I, where a forward primer was designed for each of the two subclades (Fig. 2, clades Ia and Ib) because of the difficulty in finding a common region in the $\mathrm{CP}$ nucleotide sequences. The specificity of each primer used in combination with NGRRM-TL-CPR was confirmed by analyzing reactions from five source trees (Supplemental Figure 1) and supported by direct sequencing of the amplicons.

RT-PCR with the virus-specific primers was used to assess successful transmission of viruses to woody indicators (Table 3). Of 66 inoculations of woody indicators, inoculations from five source trees, 10 inoculations in total, failed to result in transmission of virus sequences as determined by RT-PCR. Comparison of these data can resolve some of the incongruences observed in symptom development on woody indicators. CRMaV was not transmitted from 8079-1 to 'Bing' or 'Sam' although this virus was detected in the source tree. This accounts for the absence of symptoms in the 'Bing' and 'Sam' indicators. Interestingly, epinasty was observed on the 'Kwanzan' indicator for CGRMV inoculated with the same bud source, and CGRMV was transmitted to all three indicators. The reason for the failure to transmit CRMaV versus CGRMV is not known. Conversely, failed transmission of CGRMV from sources 95CI189R2 and 95CI205R1 was indicated by the absence of symptoms on 'Kwanzan' and supported by negative RT-PCR results.

The six CTLD sources all induced twisted leaf symptoms on the indicator 'Bing'. This is consistent with the predicted positive reaction with primer CTL-1a $218 \mathrm{CPF}$ in extracts from all source trees and in the 'Bing' woody indicators. It is also noteworthy that inoculation with any of the CTLD sources trees induced a chlorotic mottle on 'Bing' and a mild rusty mottle on 'Sam'. Compared with symptoms induced by inoculation with CRMD sources that produced symptoms within 45 days, symptoms produced by CTLD sources were milder and only appeared 75 days after inoculation. Furthermore, none of these source trees had CRMaV

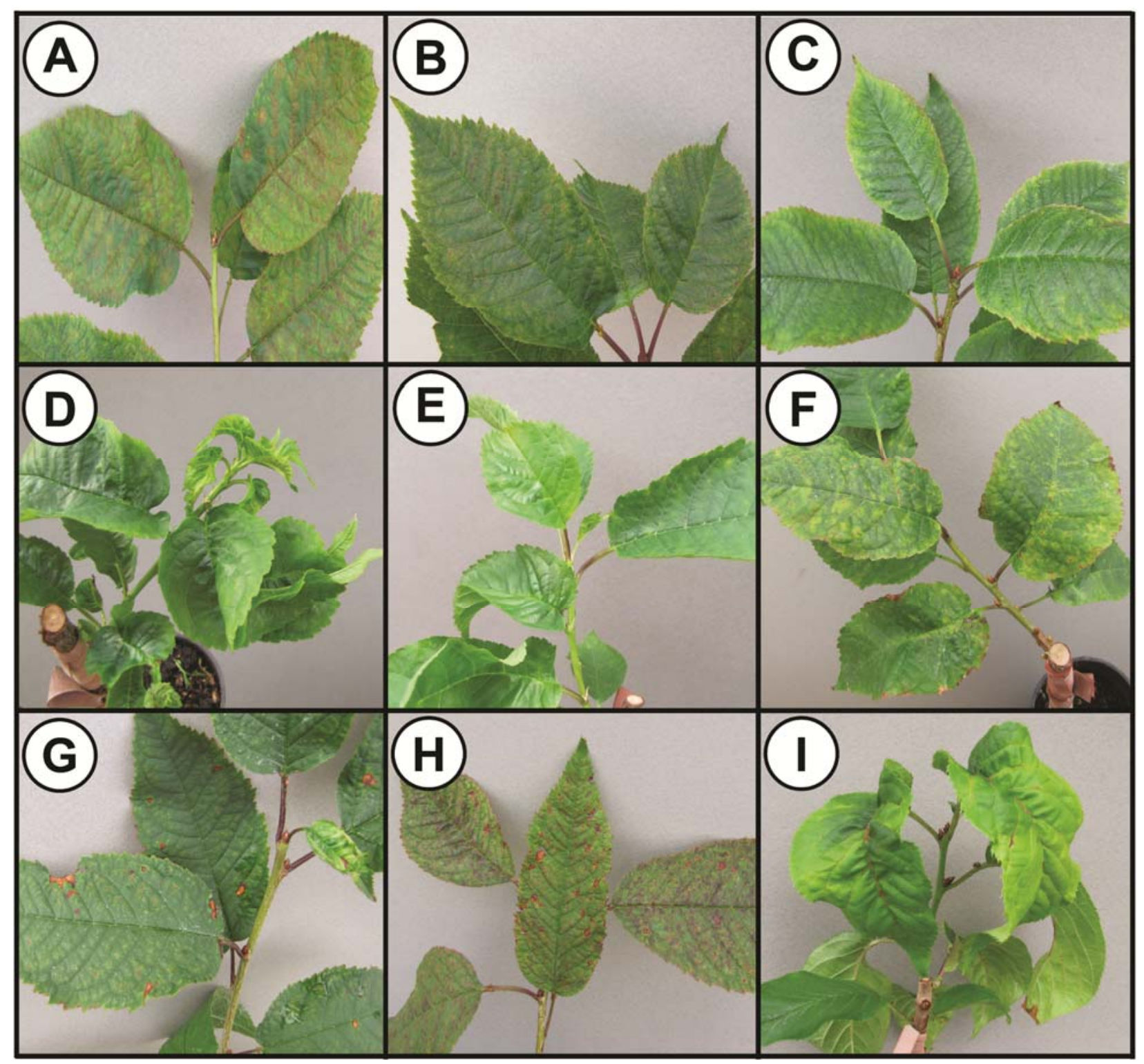

Fig. 1. Representative symptoms induced by disease sources on woody indicators. A to $\mathbf{C}$, Severe rusty mottle, rusty mottle, and chlorotic yellow mottle symptoms, respectively, induced by cherry rusty mottle disease sources on 'Bing'; $\mathbf{D}$ and $\mathbf{E}$, twisted leaf and mild twisted leaf symptoms, respectively, of cherry twisted leaf disease on 'Bing'; F, chlorotic mottle symptoms on 'Bing' induced by cherry twisted leaf disease source 8242-3; G and H, necrotic spots and necrotic spots with rusty mottle, respectively, of cherry necrotic rusty mottle disease symptoms on 'Sam'; and I, severe epinasty and vein necrosis cherry green ring mottle disease symptoms on 'Kwanzan'. Photo was taken 90 days after graft inoculation. 
sequences and only two had CNRMV sequences, suggesting that the additional mottle symptoms are closely associated with CTLaV. The ARPD source 95CI205R1 did not induce symptoms on any of the indicators, although the RT-PCR analysis showed that CTLaV was successfully transmitted to 'Bing' and 'Sam'. CNRMV sources 103-13 and 95CI189R2 also contained CTLaV sequences but did not induce typical twisted leaf symptoms on 'Bing', suggesting possible interference in symptom expression in this combination of mixed infection.

All four CNRMD sources induced the expected necrotic spots when inoculated onto the indicator 'Sam'. This is consistent with symptoms described in the literature. Two sources (95CI189R2 and 95CI190) also induced mottling on 'Bing'. Analysis of the virus sequences present in these tissues indicated that the source trees also harbored sequences associated with CRMD.

The results of the biological indicator study and molecular analysis with specific primers provide a convincing association between the disease and the designated virus sequences. The robustness of this association is supported by the clustering of each designated virus sequence to a distinct clade in the phylogram. These data also illustrate the frequency of mixed infections in cherry trees. The presence of three or more sequences indicative of members of the Betaflexiviridae in many trees contributes to the difficulty in establishing the concrete link between a virus sequence and specific disease symptoms.

Potential recombination events within the CP and $3^{\prime}$-UTR regions. In total, 11 putative recombination events were detected by at least five programs of the RDP3 software (Table 5). Of 11 predicted recombinant sequences, 8 resulted from recombination between different virus species whereas 3 of 11 arose within virus species. A strong support for the occurrence of between-virus species recombination events is evident by the presence of incongruent phylogenetic groupings of the eight recombinant sequences when phylogenetic relationships were assessed using $\mathrm{CP}$ coding, 3'-UTR, and combined CP and $3^{\prime}$-UTR sequences (Table 5; Supplemental Figure 2).

\section{DISCUSSION}

Preliminary use of primer pair Fovea2/AdPr in RT-PCR of samples from CTLD- and ARPD-affected trees yielded amplicons whose sequences were closely related to CGRMV and CNRMV

TABLE 3. Summary of symptoms and reverse-transcription polymerase chain reaction results using virus specific primers in Prunus avium 'Bing' and 'Sam' and P. serrulata 'Kwanzan' graft-inoculated indicators and in the original wood of individual sources

\begin{tabular}{|c|c|c|c|c|c|c|c|c|c|c|c|c|c|c|c|c|c|c|c|c|c|c|c|}
\hline \multirow[b]{3}{*}{ Source $^{\mathrm{a}}$} & & & & \multicolumn{20}{|c|}{ Forward primer paired with common NGRRM-TL CPR reverse primer ${ }^{c}$} \\
\hline & \multicolumn{3}{|c|}{ Symptoms on woody indicators ${ }^{b}$} & \multicolumn{4}{|c|}{ CTL-Ia 218} & \multicolumn{4}{|c|}{ CTL-Ib 235} & \multicolumn{4}{|c|}{ CNRM 122} & \multicolumn{4}{|c|}{ CRM 91} & \multicolumn{4}{|c|}{ CGRM 98} \\
\hline & B & $\mathrm{S}$ & $\mathrm{K}$ & $\mathrm{O}$ & B & $\mathrm{S}$ & $\mathrm{K}$ & $\mathrm{O}$ & B & $\mathrm{S}$ & $\mathrm{K}$ & $\mathrm{O}$ & B & $\mathrm{S}$ & $\mathrm{K}$ & $\mathrm{O}$ & B & $\mathrm{S}$ & $\mathrm{K}$ & $\mathrm{O}$ & B & $\mathrm{S}$ & $\mathrm{K}$ \\
\hline \multicolumn{24}{|l|}{ CRMD } \\
\hline $95 \mathrm{CI} 192 \mathrm{R} 3^{\mathrm{d}}$ & RMo & RMo & ns & - & - & - & - & - & - & - & - & - & - & - & - & + & + & + & + & - & - & - & - \\
\hline $\mathrm{B} 48-\mathrm{C}^{\mathrm{d}}$ & sRMo & sRMo & CYMo & - & - & - & - & - & - & - & - & - & - & - & - & + & + & + & + & - & - & - & - \\
\hline $99 \mathrm{CI} 01^{\mathrm{d}}$ & RMo & RMo & CYMo, E & - & - & - & - & + & + & + & + & - & - & - & - & + & + & + & + & + & + & + & + \\
\hline $98 \mathrm{CI} 194^{\mathrm{d}}$ & sRMo & sRMo & $\mathrm{CMo}, \mathrm{CR}$ & - & - & - & - & - & - & - & - & - & - & - & - & + & + & + & + & - & - & - & - \\
\hline $04 \mathrm{E} 17 \mathrm{R} 1^{\mathrm{d}}$ & CYMo & sRMo & nbt & - & - & - & $\mathrm{n} / \mathrm{d}$ & - & - & - & $\mathrm{n} / \mathrm{d}$ & + & + & + & $\mathrm{n} / \mathrm{d}$ & + & + & + & $\mathrm{n} / \mathrm{d}$ & + & + & + & $\mathrm{n} / \mathrm{d}$ \\
\hline $8099-5$ & CYMo & RMo & mCMo & - & - & - & - & - & - & - & - & - & - & - & - & + & + & + & + & - & - & - & - \\
\hline $8241-2$ & RMo & sRMo & CYSp & - & - & - & - & - & - & - & - & - & - & - & - & + & + & + & + & - & - & - & - \\
\hline $8079-1$ & ns & $\mathrm{ns}$ & E & - & - & - & - & - & - & - & - & - & - & - & - & + & - & - & - & + & + & + & + \\
\hline 98CI73R1 & sRMo & sRMo & CMo & - & - & - & - & - & - & - & - & - & - & - & - & + & + & + & + & - & - & - & - \\
\hline \multicolumn{24}{|l|}{ CTLD } \\
\hline $103-15^{\mathrm{d}}$ & TLf, CMo & mRMo & $\mathrm{sE}, \mathrm{NV}$ & + & + & + & + & - & - & - & - & - & - & - & - & - & - & - & - & + & + & + & + \\
\hline $101-13$ & TLf, CMo & mRMo & sE, NV, CMo, CR & + & + & + & + & - & - & - & - & - & - & - & - & - & - & - & - & + & + & + & + \\
\hline $8242-3$ & mTLf, CMo & mRMo & sE, CMo, CR & + & + & + & + & - & - & - & - & - & - & - & - & - & - & - & - & + & + & + & + \\
\hline $8241-4$ & mTLf, mCMo & mRMo & ns & + & + & + & + & - & - & - & - & - & - & - & - & - & - & - & - & + & + & + & - \\
\hline 8265 & mTLf, mCMo & mRMo & sE, CMo, NV & + & + & + & $\mathrm{n} / \mathrm{d}$ & - & - & - & $\mathrm{n} / \mathrm{d}$ & + & + & + & $\mathrm{n} / \mathrm{d}$ & - & - & - & - & + & + & + & $\mathrm{n} / \mathrm{d}$ \\
\hline 95CI191R3 & mTLf, CMo & ns & sE, NV & + & + & + & + & - & - & - & - & + & + & + & + & - & - & - & - & + & + & + & + \\
\hline \multicolumn{24}{|l|}{ CNRMD } \\
\hline $103-13^{\mathrm{d}}$ & ns & NSp, mRMo & CMo & + & + & + & + & - & - & - & - & + & + & + & + & - & - & - & - & - & - & - & - \\
\hline $04 \mathrm{E} 36$ & ns & $\mathrm{NSp}$ & ns & - & - & - & - & - & - & - & - & + & + & + & + & - & - & - & - & - & - & - & - \\
\hline 95CI189R2 & CYMo & NSp, RMo & CMo, CR & + & - & - & - & + & + & + & + & + & + & + & + & + & + & + & + & + & - & - & - \\
\hline 95CI190 & RMo & NSp, RMo & CYMo, E & - & - & - & - & - & - & - & - & + & + & + & + & + & + & + & + & + & + & + & + \\
\hline \multicolumn{24}{|l|}{ CGRMD } \\
\hline $02 \mathrm{~F} 23 \mathrm{rD}$ & ns & ns & sE, NV & - & - & - & - & - & - & - & - & - & - & - & - & - & - & - & - & + & + & + & + \\
\hline \multicolumn{24}{|l|}{ ARPD } \\
\hline $95 \mathrm{CI} 205 \mathrm{R} 1^{\mathrm{d}}$ & ns & ns & ns & - & - & - & - & + & + & + & - & - & - & - & - & - & - & - & - & + & - & + & - \\
\hline \multicolumn{24}{|l|}{ Unknown } \\
\hline $8244-4$ & ns & ns & ns & - & - & - & - & - & - & - & - & + & - & + & + & - & - & - & - & - & - & - & - \\
\hline
\end{tabular}

${ }^{a}$ CRMD $=$ cherry rusty mottle disease, CTLD = cherry twisted leaf disease, CNRMD = cherry necrotic rusty mottle disease, CGRMD = cherry green ring mottle disease, and ARPD = apricot ring pox.

${ }^{\mathrm{b}}$ Rusty mottle $(\mathrm{RMo})=$ appearance of chlorotic yellow mottle, chlorotic rings and reddish brown lesions covering <25\% of leaf area; severe rusty mottle $(\mathrm{sRMo})=$ similar to RMo, with $>25 \%$ of the leaf area being covered with reddish brown lesions; mild rusty mottle $(\mathrm{mRMo})=$ similar to RMo, with very few red lesions that become visible only at 75 days after graft inoculation; chlorotic yellow mottle (CYMo) = similar to RMo, without reddish-brown coloration of the leaves; chlorotic mottle $(\mathrm{CMo})=$ light green mottle on the leaves, without turning yellow; chlorotic rings $(\mathrm{CR})=$ small red circles or rings on the leaves; twisted leaf $($ TLf $)=$ abrupt kink in the leaf midrib, causing it to appear twisted and distorted and accompanied by downward and side curling and shortening of the internodes, causing the spurs to appear bunchy; mild twisted leaf $(\mathrm{mTLf})=$ slight side curling and twisting in the majority of the leaves; epinasty $(\mathrm{E})=$ downward bending of the leaves; severe epinasty $(\mathrm{sE})=$ same as $\mathrm{E}$ but includes leaf rolling and curling; necrotic vein $(\mathrm{NV})=$ necrosis in the leaf midrib to the lateral veins; ns $=$ no symptom; and $\mathrm{nbt}=$ no bud-take.

${ }^{c}$ The following coat protein forward (CPF) primers are specific for the following virus: CTL-Ia 218 and CTL-Ib 235 for Cherry twisted leaf associated virus (CTLaV), CNRM 122 for Cherry necrotic rusty mottle virus (CNRMV), CRM 91 for Cherry rusty mottle associated virus (CRMaV), and CGRM 98 for Cherry green ring mottle virus $(\mathrm{CGRMV}) . \mathrm{O}=$ original wood, $\mathrm{B}=P$. avium 'Bing', $\mathrm{S}=P$. avium 'Sam', and $\mathrm{K}=$ P. serrulata 'Kwanzan'; + and - indicate that the source is tested positive and negative, respectively, for the particular virus assayed whereas not determined (n/d) means that no test was done for the particular source.

${ }^{\mathrm{d}}$ Disease source trees that were indexed twice on 'Bing', 'Sam', and 'Kwanzan' indicators. Results obtained in the first and second indexing for these trees were identical. 
(K. C. Eastwell, unpublished data). This primer pair also amplified regions of the CNRMV, CGRMV, and CRMaV genomes (36). These data were extended, and subsequent phylogenetic analysis of sequences generated from 24 source trees along with

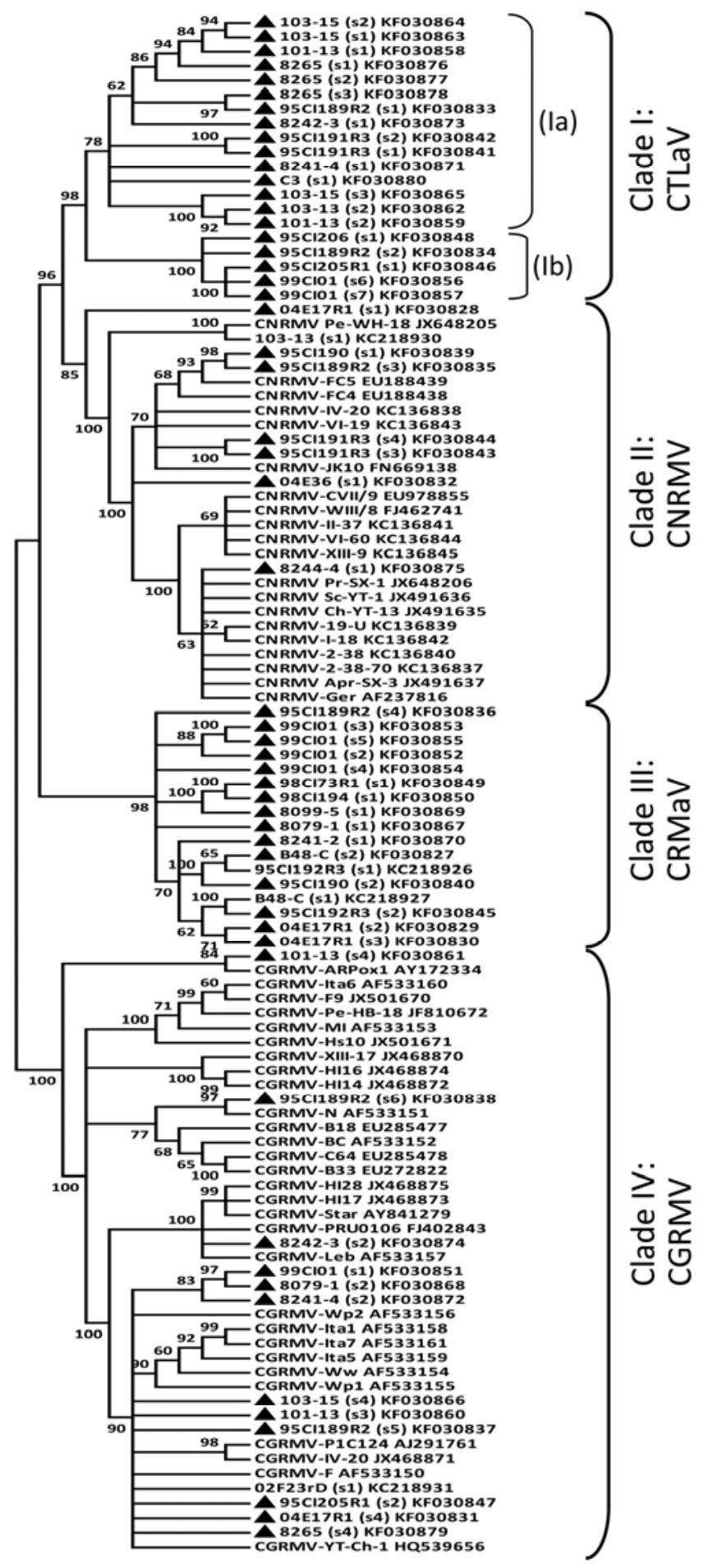

Fig. 2. Phylogenetic analysis of the coat protein nucleotide sequence of viruses associated with cherry twisted leaf, apricot ring pox, cherry necrotic rusty mottle, cherry rusty mottle, and cherry green ring mottle (CGRM) diseases. Trees were constructed using the neighbor-joining method with 1,000 bootstrap replicates of the MEGA program package, version 5. Branch nodes $<60 \%$ bootstrap values are collapsed. Individual sequences recovered from a given source are denoted by the sequence number in parenthesis after the source name. The Ia and Ib designation within the Cherry twisted leaf associated virus (CTLaV) clade correspond to the specificity of the two forward primers for this virus; $\boldsymbol{\Delta}$ indicates sequences obtained in this study. CNRMV, Cherry necrotic rusty mottle virus; CRMaV, Cherry rusty mottle associated virus; and CGRMV, Cherry green ring mottle virus. known CGRMV and CNRMV sequences from other geographic regions revealed resolution of sequences into four major clades. Each of these clades is associated with the development of specific disease symptoms associated with either one of the rusty mottle group of diseases, CGRMD or CTLD.

Variations in CRMD symptoms were noted on the two indicators 'Bing' and 'Sam' but the resulting phylogenetic clustering of CRMaV CP sequences did not correlate with differences in symptom severity. The variation in symptoms may be the consequence of mixed infections or symptom severity determinants for $\mathrm{CRMaV}$ that reside in regions of the virus genome other than the CP or 3'-UTR. The original distinction between mild and severe types of CRMD (24) was based on assessment of field disease symptoms and may not be consistent with the designation of mild and severe produced on the greenhouse-grown indicators. Based on limited field symptom observations, all CRMD sources used in this study were comparable with the severe type of CRMD (24). Moreover, all CRMaV sequences in clade III pertain to CRMD isolates obtained from North American sources. The distinction between North American and European types is exemplified by the absence from the graft-inoculated 'Bing' and 'Sam' of the concentration of rusty mottle symptoms along the leaf vein characteristic of the European isolates (31). It would be valuable in the future to determine whether the European type of CRMD-associated virus sequences are related those derived in this study.

The ARPD sources used were established disease reference sources and not from recent field collections. It was previously established by reciprocal graft transmission studies that several but not all known ARPD source trees induce CTLD on 'Bing' sweet cherry and a number of known CTLD sources cause ARPD disease on 'Wenatchee' apricot (18). Woody indexing results of ARPD source 95CI205R1 indicate that this source is non-CTLD inducing because of the absence of CTLD symptoms in 'Bing', although RT-PCR analysis provided evidence of successful virus transmission to this indicator. Phylogenetic analysis did not reveal a distinct division within the CTLaV clade that could be specifically associated with the ARPD-inducing strains. Taken together, the clustering of virus sequences associated with CTLD and ARPD into a single clade (CTLaV) corroborates the previous assertion on the close relationship of the agents causing CTLD and ARPD $(8,18)$. Alternatively, the differences in symptom expression may be related to the presence of mixed infections. CTLD sources 103-15 and 101-13 that exhibited typical twisted leaf symptoms were also infected with Cherry mottle leaf virus (CMLV, genus Trichovirus) whereas the other CTLD sources displayed a milder expression of twisted leaf symptoms (Table 3 ). CTLD source 8265 expressed mild CTLD but it also was infected with CMLV. Pairwise sequence comparison of the CTLD 8265 amplicon generated from the CMLV RT-PCR test showed $84 \%$ nucleotide identity to the corresponding CMLV amplicons from CTLD sources 103-15 and 101-13. Both CMLV amplicons from CTLD 103-15 and 101-13 shared $>98 \%$ nucleotide sequence identities. These results suggest that CTLD sources 103-15 and 101-13 are infected with the same CMLV strains whereas a different CMLV strain is present CTLD 8265. Thus, the severity of CTLD symptom expression may be governed by the particular strain of co-infecting CMLV.

Evidence of infection by other common pathogens in individual source trees was sought to determine whether other pathogens may have contributed to symptom development. The presence of PDV, CVA, and PNRSV in source trees was not surprising because these viruses are known to be widespread in sweet cherry $(5,13,23,33)$. No obvious symptoms have been reported in association with CVA $(5,13,14)$, and the presence or absence of CVA did not correlate with the intensity of symptom expression in any of the five diseases considered in this study. The same can be said on the occurrence of Apple chlorotic leafspot virus (ACLSV) in a 
few source trees. This virus occurs predominantly as latent infections in sweet cherry, although a few strains of ACLSV are presumed to synergistically interact with PNSRV to induce fruit necrosis and bark splitting on some cultivars. However, no leaf symptoms have been associated with ACLSV infection in sweet cherry trees (24).

The shock phase symptom of PNRSV infection is most similar to those of CNRMV infection. However, the necrotic spots caused by CNRMV are angular or occur in large areas of the leaves and are normally not accompanied by yellowish green borders. Of the 10 sources that were infected with PNRSV, necrotic spot symptoms were only observed on 'Sam' when inoculated with a CNRMD source tree. Additionally, of the four CNRMD sources that harbor CNRMV, only two were infected with PNRSV. Thus, the appearance of angular necrotic lesions observed in this study is specifically associated with CNRMV.

The presence of virus-specific variants is well documented in other fruit tree viruses $(3,15,22)$ and was shown to occur in the source trees examined in this study. Given the error-prone nature of the viral RNA-dependent RNA polymerase coupled with short generation times and the clonal propagation and perennial nature of sweet cherry, the detection of sequence variants in a single source is anticipated. Of greater significance is the recovery of potential recombinant virus sequences in many disease source trees that harbored infections of different viruses. A closer examination of multiple sequence alignment data (data not shown) as well as incongruent phylogenies obtained for the CP and 3'-UTR sequences provided evolutionary evidence of recombination. Phylogenetic incongruence, as an additional support for recombination, has been reported in other host-virus pathosystems
$(3,21)$. Because these viruses are closely related to each other and given their presence as mixed infections in field trees, additional recombination events in other portions of the genome are likely to occur. Because the $\mathrm{CP}$ and $3^{\prime}$-UTR constitute only $\approx 12 \%$ of the genome of the viruses considered in this study, the actual extent of recombination events in these viruses could be far greater. Future investigation to identify recombination hotspots in the virus genome will be helpful in evaluating the potential risk of emergence of new and more "virulent" virus strains or species.

Both CNRMV and CGRMV are unassigned members of the Betaflexiviridae family of plant viruses (1). The CRMaV has a carla-like replicase gene of $230 \mathrm{kDa}$ in size (36), consistent with its inclusion in this family. The nucleotide and amino acid sequence identity values in CP gene comparisons with CNRMV and CGRMV strongly suggest that CTLaV also belongs to the family Betaflexiviridae.

Within members of the Betaflexiviridae family, viruses that have $<72 \%$ nucleotide or $80 \%$ amino acid identity between their entire $\mathrm{CP}$ gene are regarded as distinct species whereas species from different genera have $<45 \%$ nucleotide or $40 \%$ amino acid identity (2). Frequency distributions of the percent nucleotide and amino acid identity values for the $\mathrm{CP}$ gene (total of 90 sequences, excluding the putative recombinant sequences) were made in order to determine whether appropriate criteria can be established to discriminate these viruses as different species in the Betaflexiviridae family (Fig. 3). On the basis of the proposal that CTLaV, CNRMV, CRMaV, and CGRMV represent distinct virus species, careful inspection of the frequency distribution data revealed two key features. (i) All pairwise nucleotide sequence comparisons between proposed virus species showed $<80 \%$

TABLE 4. Ranges of coat protein nucleotide (lower diagonal) and amino acid (upper diagonal) sequence identities the four virus clades

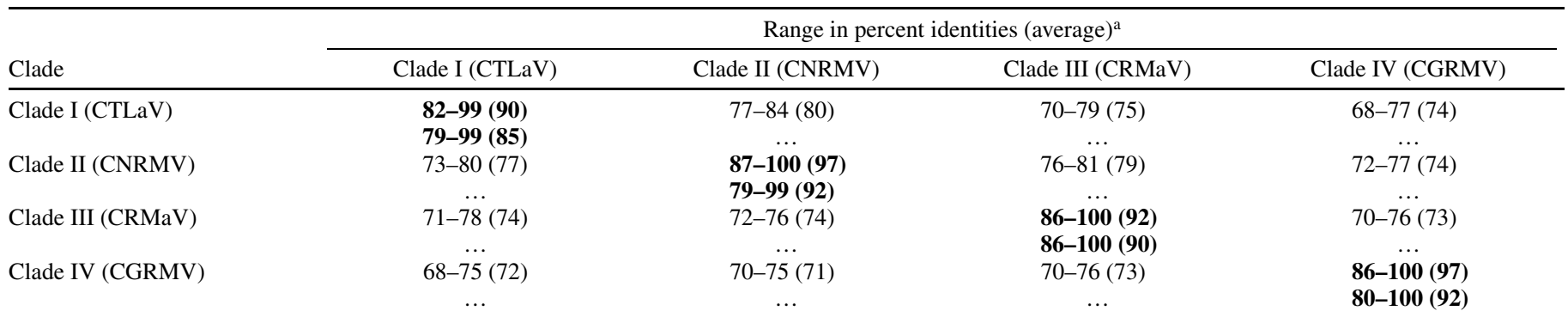

${ }^{a}$ CTLaV, Cherry twisted leaf associated virus; CNRMV, Cherry necrotic rusty mottle virus; CRMaV, Cherry rusty mottle associated virus; CGRMV, Cherry green ring mottle virus. Values enclosed in parenthesis correspond to average percentage sequence identities whereas values outside the parenthesis refer to the range of percentage sequence identities. Upper and lower values in bold pertain to amino acid and nucleotide sequence identities, respectively between members within the clade. Values above and below bold values correspond to amino acid and nucleotide percent sequence identities, respectively.

TABLE 5. Putative recombinant virus sequences in individual source tree as identified by different recombination detection methods

\begin{tabular}{|c|c|c|c|c|c|c|c|c|}
\hline \multirow[b]{2}{*}{ Recombinant } & \multicolumn{3}{|c|}{ Phylogenetic grouping ${ }^{\mathrm{a}}$} & \multirow[b]{2}{*}{ Site $^{b}$} & \multicolumn{2}{|c|}{ Parental isolates $^{\mathrm{c}}$} & \multicolumn{2}{|c|}{ Recombination detection $^{\mathrm{d}}$} \\
\hline & $\mathrm{CP}$ and $3^{\prime}$-UTR & $\mathrm{CP}$ & $3^{\prime}$-UTR & & Major & Minor & Methods & $P$ value \\
\hline 99CI01 (s4) & CRMaV & CRMaV & CTLaV & 464-1002 & 99CI01 (s2) & 99CI01 (s6) & $\mathrm{R}, \mathrm{G}, \mathrm{B}, \mathrm{M}, \mathrm{C}, \mathrm{S}, \mathbf{3 S}, \mathrm{L}$ & $8.39 \times 10^{-29}$ \\
\hline 99CI01 (s5) & CRMaV & CRMaV & CTLaV & $824-1000$ & 99CI01 (s2) & 99CI01 (s6) & $\mathbf{G}, \mathbf{M}, \mathrm{C}, \mathrm{S}, 3 \mathrm{~S}$ & $2.52 \times 10^{-19}$ \\
\hline $103-15(s 4)$ & CGRMV & CGRMV & CTLaV & $600-991$ & $101-13(\mathrm{~s} 3)$ & $103-13(\mathrm{~s} 1)$ & $\mathrm{R}, \mathrm{G}, \mathrm{M}, \mathrm{C}, \mathrm{S}, \mathbf{3 S}, \mathrm{L}$ & $1.96 \times 10^{-22}$ \\
\hline $8241-4(\mathrm{~s} 2)$ & CGRMV & CGRMV & CTLaV & $825-992$ & 02F23rD (s1) & $103-13(\mathrm{~s} 1)$ & $\mathrm{R}, \mathbf{G}, \mathrm{M}, \mathrm{C}, \mathrm{S}, 3 \mathrm{~S}, \mathrm{~L}$ & $2.98 \times 10^{-18}$ \\
\hline 95CI189R2 (s6) & CGRMV & CGRMV & CRMaV & $755-998$ & CGRMV-N & 95CI189R2 (s4) & $\mathrm{R}, \mathrm{G}, \mathrm{M}, \mathrm{C}, \mathrm{S}, \mathbf{3 S}, \mathrm{L}$ & $1.93 \times 10^{-36}$ \\
\hline 99CI01 (s2) & CRMaV & CRMaV & CGRMV & $1-685$ & $8242-3(\mathrm{~s} 2)$ & $8241-2(\mathrm{~s} 1)$ & $\mathrm{R}, \mathrm{G}, \mathrm{M}, \mathrm{C}, \mathrm{S}, \mathbf{3 S}, \mathrm{L}$ & $9.36 \times 10^{-17}$ \\
\hline 99CI01 (s3) & CRMaV & CRMaV & CGRMV & $99-686$ & $8242-3(\mathrm{~s} 2)$ & $8241-2(\mathrm{~s} 1)$ & $\mathrm{R}, \mathrm{G}, \mathrm{M}, \mathrm{C}, \mathrm{S}, 3 \mathrm{~S}, \mathrm{~L}$ & $1.11 \times 10^{-9}$ \\
\hline 95CI191R3 (s3) & CNRMV & CNRMV & CTLaV & $2-857$ & 95CI191R3 (s1) & 95CI191R3 (s4) & $\mathrm{M}, \mathrm{C}, \mathrm{S}, \mathbf{3 S}, \mathrm{L}$ & $1.23 \times 10^{-25}$ \\
\hline $8265(\mathrm{~s} 2)$ & CTLaV & CTLaV & CTLaV & $390-870$ & $8265(\mathrm{~s} 1)$ & $8265(\mathrm{~s} 3)$ & $\mathrm{G}, \mathrm{B}, \mathrm{M}, \mathrm{C}, \mathrm{S}, \mathbf{3 S}, \mathrm{L}$ & $5.06 \times 10^{-20}$ \\
\hline $103-15(\mathrm{~s} 2)$ & CTLaV & CTLaV & CTLaV & $764-1003$ & $103-15(\mathrm{~s} 1)$ & $103-15(\mathrm{~s} 3)$ & $\mathrm{G}, \mathrm{M}, \mathrm{C}, \mathrm{S}, \mathbf{3 S}, \mathrm{L}$ & $2.55 \times 10^{-17}$ \\
\hline 95CI191R3 (s2) & CTLaV & CTLaV & CTLaV & $287-418$ & 95CI191R3 (s1) & 95CI191R3 (s3) & $\mathrm{G}, \mathrm{M}, \mathrm{C}, \mathrm{S}, \mathbf{3 S}, \mathrm{L}$ & $5.69 \times 10^{-14}$ \\
\hline
\end{tabular}

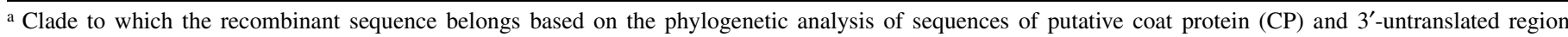
(3'-UTR), CP alone, and 3'-UTR alone. CRMaV, Cherry rusty mottle associated virus; CTLaV, Cherry twisted leaf associated virus; CGRMV, Cherry green ring mottle virus; CNRMV, Cherry necrotic rusty mottle virus.

${ }^{\mathrm{b}}$ Recombination site. Numbers indicate nucleotide positions numbered from CP to 3'-UTR.

${ }^{c}$ Parental isolates refer to the isolates that contribute to the smaller (minor parent) and larger (major parent) sequence tracts in the recombinant sequence.

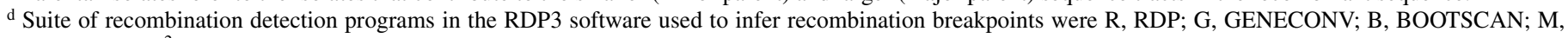
MAXIMUM $\chi^{2}$; C, CHIMAERA; S, SISCAN; 3S, SSEQ; L, LARD. The $P$ values correspond to the methods highlighted in bold. 
identity, except for one comparison between CTLaV and CNRMV that equaled $80 \%$ identity. Within virus species, the lowest pairwise nucleotide sequence comparisons were $80 \%$, except for 3 of 136 comparisons within CTLaV and 1 of 351 within CNRMV that equaled $79 \%$. (ii) At the amino acid level, a maximum value of $82 \%$ sequence identity was observed between virus species, with the exception of 11 of 459 CTLaV versus CNRMV sequence comparisons that displayed sequence identities of 83 or $84 \%$. Within virus species, the lowest pairwise amino acid sequence comparisons were $84 \%$, except for two comparison within CTLaV that equal 82 or $83 \%$ identity.

The current guidelines for species demarcation within the family Betaflexiviridae do not adequately describe the relationships between CTLaV, CNRMV, CRMaV, and CGRMV. However, based on the assessment of the frequency distribution data, a homogeneous classification of virus sequences can be obtained using the amino acid and nucleotide sequence of the $\mathrm{CP}$ region. If the amino acid or nucleotide sequence identity of the $\mathrm{CP}$ sequences are $\geq 84$ or $\geq 80 \%$, respectively, then the viruses belong to the same species. To resolve a minority of situations where classification is ambiguous, it is proposed that the sequence in question would be assigned to the virus species to which it holds greater identity. The results of this analysis impose an immediate need to examine whether the replicase coding region frequency distribution data for this group of viruses will be parallel to that of the $\mathrm{CP}$ sequence data. This requires full genome sequencing of representative isolates of CTLaV because there are no CTLaV replicase sequences currently available in public databases.

In summary, the putative $\mathrm{CP}$ virus sequences recovered from individual sources used in this study were phylogenetically grouped and correlated carefully with symptoms induced in different woody indicators. Inconsistencies observed in data from

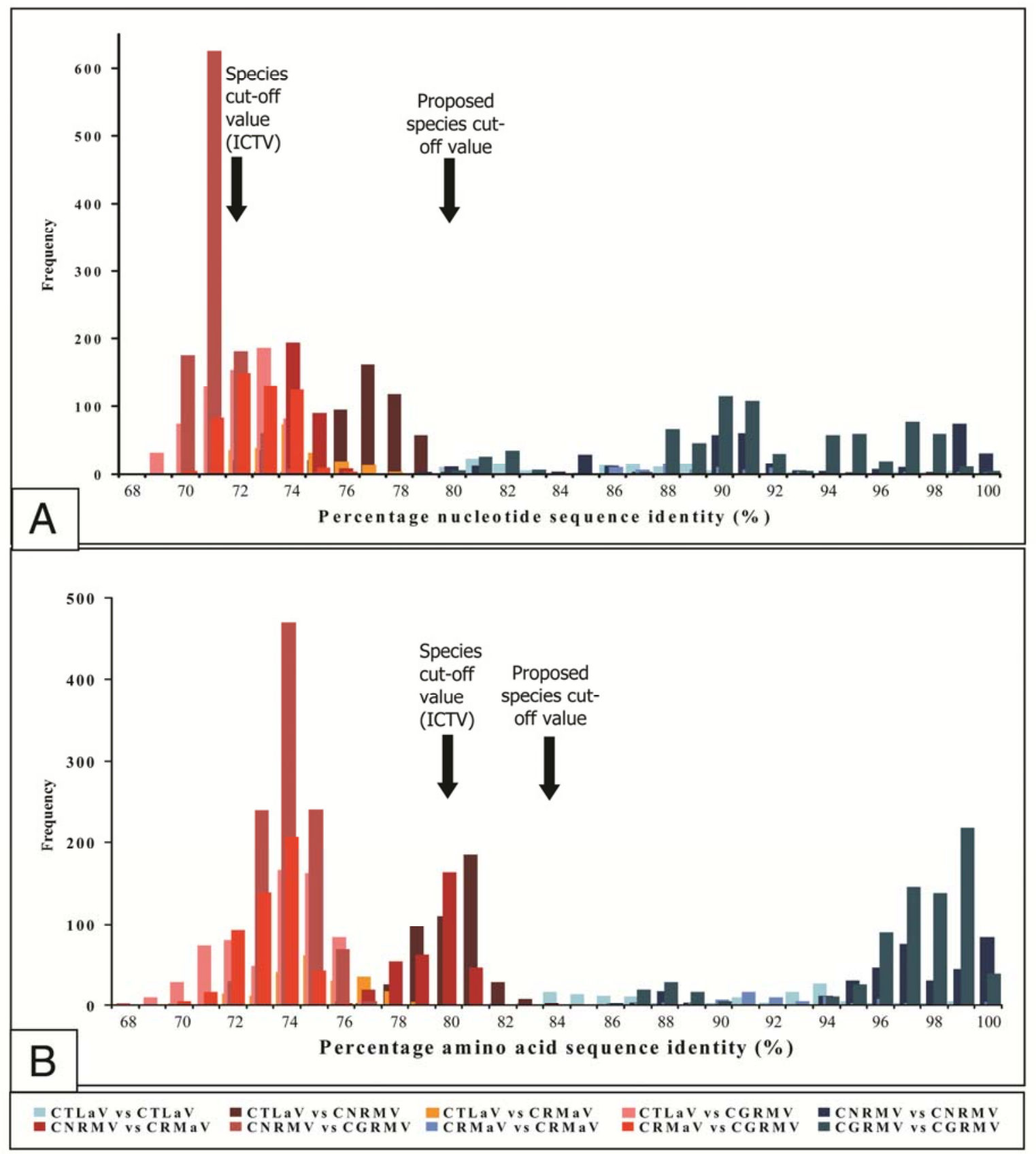

Fig. 3. Frequency distribution of the percentage of $\mathbf{A}$, nucleotide and $\mathbf{B}$, amino acid sequence identity from pairwise comparisons of the full coat protein coding sequence $(n=90)$ of Cherry twisted leaf associated virus (CTLaV), Cherry necrotic rusty mottle virus (CNRMV), Cherry rusty mottle associated virus (CRMaV), and Cherry green ring mottle virus (CGRMV). Arrows indicate the International Committee on Taxonomy of Viruses and proposed sequence identity cut-off values for species discrimination. 
some sources were addressed by the development of specific RTPCR tests for individual virus. Taken together, a robust association of virus sequences with disease was completed, making this the first comprehensive assessment of the association of virus sequences corresponding to CTLD and ARPD, CNRMD, CRMD, and CGRMD. This study is also the first thorough evaluation on the molecular relationships of the associated viruses with one another. An immediate application of the newly designed primers for RT-PCR is that a specific molecular assay for each virus will complement the existing biological woody indexing program undertaken annually at clean plant centers around the world.

\section{ACKNOWLEDGMENTS}

This work was supported, in part, by the Department of Plant Pathology, College of Agricultural, Human, and Natural Resource Sciences Agricultural Research Center Project Number WNP00754, Washington State University, Pullman 99164-6240. This work was also supported, in part, by funding from the Washington State Tree Fruit Research Commission and the National Clean Plant Network of the United States Department of Agriculture Animal and Plant Health Inspection Service (USDA-APHIS). We thank M. Bernardy of the Canadian Plant Virus Collection, Agriculture and Agri-Food Canada, Summerland, $\mathrm{BC}$, Canada, for kindly providing material of ARPD source tree $\mathrm{C} 3$ under USDA-APHIS permit number P526P-11-02823.

\section{LITERATURE CITED}

1. Adams, M. J., Antoniw, J. F., Bar-Joseph, M., Brunt, A. A., Candresse, T., Foster, G. D., Martelli, G. P., Milne, R. G., and Fauquet, C. M. 2004. The new plant virus family Flexiviridae and assessment of molecular criteria for species demarcation. Arch. Virol. 149:1045-1060.

2. Adams, M. J., Candresse, T., Hammond, J., Kreuze, J. F., Martelli, G. P., Namba, S., Pearson, M. N., Ryu, K. H, Saldarelli, P., and Yoshikawa, N. 2012. Family Betaflexiviridae. Pages $920-941$ in: Virus Taxonomy: Ninth Report of the International Committee on Taxonomy of Viruses. A. M. Q King, M. J. Adams, E. B. Carstens, and E. J. Lefkowitz eds. Elsevier Academic Press, London.

3. Alabi, O. J., Martin, R. R., and Rayapati, N. 2010. Sequence diversity, population genetics and potential recombination events in grapevine rupestris stem pitting-associated virus in Pacific North-West vineyards. J. Gen. Virol. 91:265-276.

4. Coe, D. M. 1943. Report of the 1942 stone fruit virus disease survey of Washington. Wash. State Dep. Agric. Bull. No. 2.

5. Eastwell, K. C., and Bernardy, M. G. 1998. Relationship of cherry virus A to little cherry disease in British Columbia. Acta Hortic. 472:305-313.

6. Gentit, P., Foissac, X., Svanella-Dumas, L., Peypelut, M., Macquaire, G., and Candresse, T. 2002. Molecular characterization of foveaviruses associated with cherry necrotic mottle leaf disease and complete sequencing of an European isolate of Cherry green ring mottle virus. Arch. Virol. 147:1033-1042.

7. Hall, T. A. 1999. BioEdit: A user-friendly biological sequence alignment editor and analysis program for Windows 95/98/NT. Nucleic Acids Symp. Ser. 41:95-98.

8. Hansen, A. J., Parish, C. L., and Pine, S. T. 1976. Apricot ring pox. Pages 45-49 in: Virus Diseases and Noninfectious Disorders of Stone Fruits in North America. R. M. Gilmer, J. D. Moore, G. Nyland, M. F. Welsh, and T. S. Pine, eds. U.S. Dep. Agric. Agric. Handb. 437.

9. Higgins, D., Thompson, J., Gibson, T., Thompson, J. D., Higgins, D. G., and Gibson, T. J. 1994. CLUSTAL W: Improving the sensitivity of progressive multiple sequence alignment through sequence weighting, position-specific gap penalties and weight matrix choice. Nucleic Acids Res. 22:4673-4680.

10. James, D. 1992. Isolation of a high molecular weight dsRNA associated with twisted leaf disease in cherry. Can. J. Plant Pathol. 14:281-284.

11. James, D. 2011. Cherry twisted leaf disease and its associated viruses. Pages 143-146 in: Virus and Virus-like Diseases of Pome and Stone Fruits. A. Hadidi, M. Barba, T. Candresse, and W. Jelkmann, eds. American Phytopathological Society, St. Paul, MN.

12. James, D., Howell, W. E., and Martin, R. R. 1995. Identification of a flexeous virus associated with cherry twisted leaf disease. Acta Hortic. 386:86-91.

13. James, D., and Jelkmann, W. 1998. Detection of cherry virus A in Canada and Germany. Acta Hortic. 472:299-203.

14. Jelkmann, W. 1995. Cherry virus A: cDNA cloning of dsRNA, nucleotide sequence analysis and serology reveal a new plant capillovirus in sweet cherry. J. Gen. Virol. 76:2015-2024.

15. Jridi, C., Martin, J. F., Marie-Jeanne, V., Labonne, G., and Blanc, S. 2006. Distinct viral populations differentiate and evolve independently in a single perennial host plant. J. Virol. 80:2349-2357.

16. Li, R., and Mock, R. 2008. Characterization of a flowering cherry strain of Cherry necrotic rusty mottle virus. Arch. Virol. 153:973-978.

17. Lott, T. B. 1945. "Lambert mottle" a transmissible disease of sweet cherry. Sci. Agric. 27:260-262.

18. Lott, T. B., and Keane, F. W. L. 1960. The association of the virus disease twisted leaf of cherry and ring pox of apricot. Plant Dis. Rep. 44:243-245.

19. Martin, D. P., Lemey, P., Lott, M., Moulton, V., Posada, D., and Lefeuvre, P. 2010. RDP3: A flexible and fast computer program for analyzing recombination. Bioinformatics 26:2462-2463.

20. McKeown, B. J. 1994. An acetylated (nuclease-free) bovine serum albumin in a PCR buffer inhibits amplification. BioTechniques 17:246248.

21. Mekuria, T. M., Gutha, L. R., Martin, R. R., and Naidu, R. N. 2009. Genetic diversity and intra and interspecies recombination events in Grapevine fanleaf virus. Phytopathology 99:1394-1402.

22. Meng, B., Rebelo, A. R., and Fisher, H. 2006. Genetic diversity analyses of grapevine Rupestris stem pitting-associated virus reveal distinct population structures in scion versus rootstock varieties. J. Gen. Virol. 87:1725-1733.

23. Mink, G. I., and Parsons, J. L. 1965. The prevalence of some latent viruses in sweet cherry trees of various age groups in orchards in South Central Washington. Plant Dis. Rep. 49:143-145.

24. Nemeth, M. 1986. Virus, Mycoplasma and Rickettsia Diseases of Fruit Trees. Akademiai Kiado, Budapest.

25. Ohshima, K., Tomitaka, Y., Wood, J. T., Minematsu, Y., Kajiyama, H., Tomimura, K., and Gibbs, A. J. 2007. Patterns of recombination in turnip mosaic virus genomic sequences indicate hotspots of recombination. J. Gen. Virol. 88:298-315.

26. Posnette, A. 1951. Virus diseases of sweet cherries. Annu. Rep. East Mailing Res. Stn. 1950A 34:209-210.

27. Posnette, A., and Cropley, R. 1957. A canker disease of cherry trees caused by virus infection. Plant Pathol. 6:85-87.

28. Reeves, E. L. 1940. Rusty mottle, a new virosis of cherry. (Abstr.) Phytopathology 30:789.

29. Reeves, E. L., and Richards, B. L. 1946. A rusty mottle-like virus disease of the sweet cherry in Utah. (Abstr.) Phytopathology 36:409.

30. Rhoads, A. 1945. Symptom expression of rusty mottle in Utah sweet cherry orchards. Plant Dis. Rep. 29:613-614.

31. Rott, M., and Jelkmann, W. 2011. Cherry necrotic rusty mottle and cherry rusty mottle viruses. Pages 133-136 in: Virus and Virus-like Diseases of Pome and Stone Fruits. A. Hadidi, M. Barba, T. Candresse, and W. Jelkmann, eds. American Phytopathological Society, St. Paul, MN.

32. Rott, M. E., and Jelkmann, W. 2001. Complete nucleotide sequence of cherry necrotic rusty mottle virus. Arch. Virol. 146:395-401.

33. Sabanadzovic, S., Abou-Ghanem-Sabanadzovic, N., Rowhani, A., Grant, J. A., and Uyemoto, J. K. 2005. Detection of Cherry virus A, Cherry necrotic rusty mottle virus, and Little cherry virus 1 in California orchards. J. Plant Pathol. 87:173-177.

34. Stout, G. L. 1949. Cherry bark blister. Calif. Dep. Agric. Bull. 38:257-260.

35. Tamura, K., Peterson, D., Peterson, N., Stecher, G., Nei, M., and Kumar, S. 2011. MEGA5: Molecular evolutionary genetics analysis using maximum likelihood, evolutionary distance and maximum parsimony methods. Mol. Biol. Evol. Online publication. doi:10.1093/molbev/ msr121

36. Villamor, D. V., Druffel, K. L., and Eastwell, K. C. 2013. Complete nucleotide sequence of a virus associated with rusty mottle disease of sweet cherry (Prunus avium). Arch. Virol. Online publication. doi:10.1007/s00705-013-1668-9

37. Wadley, B. N., and Nyland, G. 1976. Rusty mottle group. Pages 242-249 in: Virus Diseases and Noninfectious Disorders of Stone Fruits in North America. R. M. Gilmer, J. D. Moore, G. Nyland, M. F. Welsh, and T. S. Pine, eds. U.S. Dep. Agric. Agric. Handb. 437.

38. Wang, W., Jiang, D., Niu, F., Lu, M., Wang, H., and Li, S. 2013. Complete nucleotide sequences of two isolates of cherry green ring mottle virus from peach (Prunus persica) in China. Arch. Virol. 158:707-710.

39. Zagula, K. R., Aref, N. M., and Ramsdell, D. C. 1989. Purification, serology, and some properties of a mechanically transmissible virus associated with green ring mottle disease in peach and cherry. Phytopathology 79:451-456

40. Zhang, Y. P., Kirkpatrick, B. C., Smart, C. D., and Uyemoto, J. K. 1998. cDNA cloning and molecular characterization of cherry green ring mottle virus. J. Gen. Virol. 79:2275-2281.

41. Zhang, Y. P., Mink, G. I., Tiffany, M. G., and Howell, W. E. 1992. Isolation of viruses associated with cherry twisted leaf, apricot ringpox, and apricot pit pox diseases and their relationship to apple stem pitting virus. (Abstr.) Phytopathology 82:1149. 